\title{
ANAESTHESIA MANAGEMENT OF A TERM PREGNANT PATIENT WITH GULLAIN BARRE SYNDROME POSTED FOR ELECTIVE CAESAREAN SECTION - A CASE REPORT
}

Poornima Sonkamble, Mukund Parchandekar, Suhas Jewalikar, Ashwin Sonkamble, Sadhana Kulkarni.

1. Assistant Professor, Department of Anaesthesiology, Government Medical College, Aurangabad

2. Assistant Professor, Department of Anaesthesiology, Government Medical College, Aurangabad

3. Associate Professor, Department of Anaesthesiology, Government Medical College, Aurangabad

4. Assistant Professor, Department of Anaesthesiology, Government Medical College, Aurangabad

5. Professor and Head, Department of Anaesthesiology, Government Medical College, Aurangabad

\section{CORRESPONDING AUTHOR:}

Dr. Poornima Sonkamble

254, "Anubhuti" Nandanvan Colony,

Aurangabad (Maharashtra)

PIN- 431002

E-mail: pathadepoornima@rediffmail.com

\begin{abstract}
Guillain Barre Syndrome (GBS) is an acute, inflammatory, demyelinating polyneuropathy that present with ascending, symmetrical flaccid paralysis accompanied by sensory and autonomic involvement. GBS complicating pregnancy is a rare event and the anaesthesia management of a parturient with GBS is not well defined. We report anaesthesia management and its anaesthetic implications in term pregnant patient with GBS who was posted for elective caesarean section. In this case the caesarean section was successfully carried out under general anaesthesia.
\end{abstract}

KEY WORDS: Guillain Barre Syndrome, parturient, anaesthesia management

INTRODUCTION: Guillain Barre Syndrome, a rare neurological syndrome that may occur in pregnancy either as a co-incidental or as an antecedent event. It is a high risk complication of pregnancy that requires the mobilization of multiple resources for its management [1]. We share an experience of anaesthesia management of a diagnosed case of GBS with 9 months pregnancy posted for elective cesarean section.

CASE REPORT: A 24 year, 55kg, $3^{\text {rd }}$ gravida with 9 months pregnancy having one live issue and one abortion was presented with history of fever with chills15 days back followed by loss of power in all four limbs along with difficulty in speech, inability to close eyes, constipation and retention of urine. She was diagnosed to be a case of GBS on nerve conduction study, CSF examination and positive TORCH titres (CMV). Patient received IV Immunoglobulin $400 \mathrm{mg} / \mathrm{kg} /$ day in two divided doses for 5 days after which her muscle power improved to Grade III and Grade II in upper and lower extremities respectively and she could speak with stammering speech. On $6^{\text {th }}$ day of admission, she was posted for elective lower segment caesarean section.

On the day of surgery, patient was fully conscious, cooperative and well oriented with time, place and person. Her vitals were unstable. Pulse rate ranged between 80-140/ min, systolic blood 
pressure and diastolic blood pressure ranged from $80-150 \mathrm{mmHg}$ and $60-90 \mathrm{mmHg}$ respectively. She had respiratory rate $18 / \mathrm{min}$, breath holding time of $15 \mathrm{sec}$ and single breath count of 16 . Pulse oximeter depicted her $\mathrm{SPO}_{2}$ as $98 \%$ on air. She was anemic with no other positive general examination findings. CNS examination revealed; stammering speech, bilateral facial nerve palsy, hypotonia in all four limbs, muscle power grade III in upper extremities and grade II in lower extremities, deep tendon reflexes were sluggish and planters were absent.

NBM status of the patient, high risk consent, and consent for post operative ventilatory support was confirmed. General anaesthesia with endotracheal intubation was planned for this patient. Routine monitors like ECG with defibrillator, pulse oximeter, $\mathrm{ETCO}_{2}$, NIBP were applied. Patient was catheterized with Foleys catheter and intravenous line was secured with 18G intracath. Patient was pre-oxygenated with $100 \%$ oxygen with Bain's circuit for 5 min. Induction of anaesthesia was done with inj. Propofol $60 \mathrm{mg}$ IV and under effect of inj. Atracurium15mg IV, endotracheal intubation was done with ETT No.7.5. Anaesthesia was maintained with oxygen, nitrous oxide, isoflurane and intermittent IV Atracurium.

A healthy $2.1 \mathrm{~kg}$ baby was delivered with APGAR score of $9 / 10$ and $10 / 10$ at 1 and $5 \mathrm{~min}$ respectively. Patient was sedated with inj. Midazolam $1 \mathrm{mg}$ and inj. Fentanyl $50 \mu \mathrm{g}$ IV bolus. Inj. Pitocin 20 units in slow IV drip was started to make uterus retracted. Surgery lasted for $45 \mathrm{~min}$ and at the end of surgery; reversal of muscle blockade was done with inj. Neostigmine $2.0 \mathrm{mg}$ and inj. Glycopyrrolate $0.4 \mathrm{mg}$ IV. Patient was extubated uneventfully. Intraoperatively the patient was haemodynamically same as that of preoperative period and urine output was $100 \mathrm{ml}$.

She was shifted to post anaesthesia care unit (PACU) for observation, oxygen supplementation and physiotherapy. After 48 hours she was shifted to ward. And on $10^{\text {th }}$ postoperative day stitches were removed as surgical wound was healthy. Post operative period was uneventful with no neurological worsening and patient took discharge against medical advice on $12^{\text {th }}$ postoperative day. She was advised for follow up in Medicine OPD for neurological assessment.

DISCUSSION: GBS is an acute, inflammatory, demyelinating polyneuropathy that present with ascending, symmetrical flaccid paralysis accompanied by sensory and autonomic involvement [2].

The co-existence of GBS and pregnancy is co-incidental. The clinical presentation and the natural history of GBS is same for pregnant and non-pregnant patients [1] except the gravid uterus may affect bladder control and diminish respiratory reserve. In approximately $30 \%$ of patient Campylobacter jejuni infection is an antecedent event [3]. In our patient, symptoms of GBS were preceded by history of fever with chills and association of cytomegalovirus infection was revealed by positive TORCH titers.

The risk of GBS increases for the mother during post-partum period. The probable explanation for this is that, normal pregnancy is associated with a shift away from cell-mediated immunity towards humoral immunity. The fetal-placental unit secretes cytokines e.g. interleukin 10 that down-regulates the production of other cytokines balance. Delivery might be associated with an inversion of this cytokines balance [4]. There are no fetal or neonatal manifestations of maternal GBS and breastfeeding is allowed [3]. In our case there was no neurological deterioration or improvement in the status of GBS during observation period. Further long term neurological status of the patient cannot be commented as the patient lost follow-up. 


\section{CASE REPORT}

The management of GBS includes intravenous immunoglobulin, plasmapheresis, plasma exchange and controversial use of corticosteroids along with supportive care [2, 5]. An intensive multidisciplinary approach to supportive medical management improves the prognosis of both mother and fetus. To ensure timely obstetric intervention, the progress of the pregnancy must be assessed on daily basis ${ }^{[1]}$

Regional anesthesia is not contraindicated [6]. These patients are sensitive to local anesthetic agents, probably secondary to the presence of Na-channel blocking factor. Because of high incidence of autonomic instability, slower onset epidural anesthesia may be preferred over rapid onset spinal anesthesia. Epidural anaesthesia for elective as well as emergency caesarean section was given successfully to parturient GBS patients. There was no haemodynamic instability and once the epidural block had worn off, postpartum assessment showed no neurological change from the antenatal period [7]. In contrast, worsening of neurological symptoms and potential association of epidural local anaesthetic toxicity has been reported [4].

There is demyelination or axonal degeneration which produces functional denervation of muscle and up-regulation of n-acetyl-choline receptors at post-synaptic membrane. Scoline should be avoided because of the risk of hyperkalemic cardiac arrest [8]. This risk may persist even after recovering from the symptomatic neurological deficit [9]. Sodium channel blockade at neuro-muscular junction (NMJ) along with loss of motor unit, increases sensitivity to non-depolarising neuromuscular blocking agents. Hence their dose should be reduced [6].

One of the most important considerations is required for autonomic dysfunction, as it is seen in nearly $60 \%$ of GBS patients. Usual features are loss of vasomotor control with wide fluctuation of blood pressure, postural hypotension and cardiac dysrhythmias which can be fatal. Hence careful attention should be paid to maintenance of adequate preload, temperature control, postural changes and blood loss [6]. The presence of autonomic involvement is not clearly related to the severity of the motor or sensory involvement [10]. Even though autonomic dysfunction causes alarming pulse and BP changes, one should intervene only if the adequacy of circulation is threatened.

There are no established guidelines for anesthetic management of GBS parturient [4]. Haemodynamic stability is better maintained in general anaesthesia than regional anaesthesia. Unstable pulse and blood pressure due to autonomic involvement was the main consideration for giving general anaesthesia to our patient. No active management was needed for autonomic dysfunction. Dose reduction of non-depolarizing muscle relaxant and its successful reversal by anticholinesterase alleviated the need for post-operative ventilatory support.

In conclusion, risk-benefit ratio of general anaesthesia versus regional anaesthesia should be the mainstay in managing GBS parturient with autonomic dysfunction for caesarean section. Type of anaesthesia and its inherent risk due to disease process should be discussed with the patient and relatives for better management.

\section{REFERENCES:}

1. Laufenburg HF, Sirus SR. Guillain- Barre syndrome in pregnancy. Am Fam Physician. 1989 May; 39(5):147-50. 


\section{CASE REPORT}

2. Hall JB, Schmidt GA, Wood LD. Principles of critical care, $3^{\text {rd }}$ ed. New York, McGraw- Hill. Medical Publishing Division 2005, Chapter 66. Neuromuscular disease leading to respiratory failure. By William A Marinelli, James W Leatherman. Pg 1026-27

3. Burrow, Duffy and Copel. Medical complication during pregnancy. $6^{\text {th }}$ ed. Philadelphia. Elsevier Saunders, 2004. Chapter 19, Neurological complication; pg. 416-417.

4. Wiertlewski S, Magot A, Drapier S, malinovsky JM, pereon Y. Worsening of neurological symptoms after epidural anesthesia for labour in a Guillain Barre patient. Anesth Analg. 2004 Mar; 98(3):825-7.

5. Griffin JW and Sheikh K. Peripheral Neuropathy. $4^{\text {th }}$ ed. By Peter J Dyck and P K Thomas. Chapter 98, The Guillain Barre Syndromes; p. 2197-2219.

6. Miller R, Fleisher L, Johns R et al, Miller's Anaesthesia, 6 ${ }^{\text {th }}$ ed; Philadelphia, Elsevier Churchill Livingstone,2005, chapter 13, Pharmacology of muscle relaxant; pg 534.

7. Brooks H, Christian AS and May AE. Pregnancy, Anaesthesia and Guillain Barre Syndrome. Anaesthesia, 2000, 55, 894-898.

8. Dalman JE, Verhagen WI. Cardiac arrest in Guillain- Barre syndrome and the use of suxamethonium. Acta Neurol Belg. 1994; 94(4):259-61.

9. Feldman JM. Cardiac arrest after succinylcholine administration in a pregnant patient recovered from Guillain- Barre syndrome. Anesthesiology.1990 May;72(5):942-44

10. Kasper, Braunwald, Fauci, et al, Harrison's Principles of Internal Medicine, Stephen L Hauser, Aurthur K Asbury. 16 ${ }^{\text {th }}$ ed. USA McGraw- Hill companies, 2005. Chapter 365, Guillain Barr syndrome and other immune-mediated neuropathies; p. 2513-2517 